ARTICLE

\title{
$d$-Orbital steered active sites through ligand editing on heterometal imidazole frameworks for rechargeable zinc-air battery
}

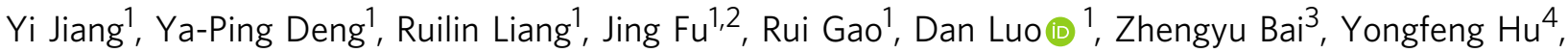
Aiping $\mathrm{Yu}^{1} \&$ Zhongwei Chen (10) ${ }^{1 凶}$

The implementation of pristine metal-organic frameworks as air electrode may spark fresh vitality to rechargeable zinc-air batteries, but successful employment is rare due to the challenges in regulating their electronic states and structural porosity. Here we conquer these issues by incorporating ligand vacancies and hierarchical pores into cobalt-zinc heterometal imidazole frameworks. Systematic characterization and theoretical modeling disclose that the ligand editing eases surmountable energy barrier for ${ }^{*} \mathrm{OH}$ deprotonation by its efficacy to steer metal $d$-orbital electron occupancy. As a stride forward, the selected cobalt-zinc heterometallic alliance lifts the energy level of unsaturated $d$-orbitals and optimizes their adsorption/desorption process with oxygenated intermediates. With these merits, cobaltzinc heterometal imidazole frameworks, as a conceptually unique electrode, empowers zincair battery with a discharge-charge voltage gap of $0.8 \mathrm{~V}$ and a cyclability of $1250 \mathrm{~h}$ at $15 \mathrm{~mA}$ $\mathrm{cm}^{-2}$, outperforming the noble-metal benchmarks.

\footnotetext{
${ }^{1}$ Department of Chemical Engineering, Waterloo Institute for Nanotechnology, University of Waterloo, Waterloo, ON N2L 3G1, Canada. ${ }^{2}$ School of Materials Science and Engineering, Tongji University Shanghai, 201804 Shanghai, China. ${ }^{3}$ School of Chemistry and Chemical Engineering, Henan Normal University,

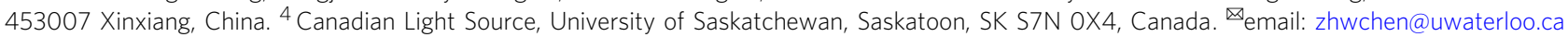


$\mathrm{R}$ echargeable $\mathrm{Zn}$-air batteries (ZABs) with four-time higher theoretical energy density, better safety, and lower cost are commonly considered as one of the most promising replacements for Li-ion batteries ${ }^{1-5}$. These superiorities mainly originate from oxygen-based electrochemistry in aqueous systems, but their full potential has yet to be realized because of high polarization and short lifespan at the air cathodes ${ }^{6-8}$. As such, the core of ZABs development lies in exploring air cathodes that are capable of efficiently catalyzing both oxygen reduction (ORR) and evolution reactions (OER) for long working periods ${ }^{9-12}$. Platinum on carbon $(\mathrm{Pt} / \mathrm{C})$ and ruthenium oxide $\left(\mathrm{RuO}_{2}\right)$ are the respective ORR and OER benchmarks, however, their applications in rechargeable ZABs are not favored due to their scarcity and inferior bifunctionality ${ }^{7,13}$. Previous attempts on economically viable electrocatalysts primarily involve inorganic candidates, such as heteroatom-doped carbon materials, metal compounds or their composites $9,14-24$. However, their electrocatalytic activity and stability are limited by dissolution or aggregation of inorganic components triggered by corrosion in highly concentrated alkaline electrolytes of oxygen free radicals emerged during battery cycling $3,25,26$.

In response, molecules with conjugated heteroaromatic organic components, such as covalent organic frameworks (COFs), hydrogen-bonded organic frameworks (HOFs) and metal-organic frameworks (MOFs), provide a possible solution to effectively resist against the attack from the oxygen free radicals ${ }^{27-29}$. As a subfamily of MOFs, zeolite imidazole frameworks (ZIFs) with excellent water and alkaline tolerance endow great promise in ZABs application ${ }^{30,31}$. Moreover, their ordered coordination manner of single metal nodes and organic ligands provides an ideal platform to regulate the electronic states of active sites and investigate their electrochemical behaviors.

However, application of ZIFs as air electrode in ZABs remains unexplored, which is ascribed to the impediments in controls over mass/charge transfer and intrinsic activity of the materials. Specifically, pristine ZIFs are mostly microporous, which usually leads to severe electrolyte flooding due to capillarity action, and thereby impedes $\mathrm{O}_{2}$ accessibility towards active sites ${ }^{10,27,32}$. Besides, their low electrical conductivity inevitably causes sluggish charge transfer ${ }^{33}$. This is often addressed by high-temperature pyrolysis, which causes the dilemma of compromising intrinsic properties, including periodic coordination structure, monodisperse metal nodes, and high surface area ${ }^{20,34}$. Additionally, the pyrolysis imposes side-effects on electrode flexibility due to the inevitable fragmentation of catalysts and degeneration of substrate (e.g., nickel foam, copper mesh, carbon cloth). Lastly, the saturated coordination environment of metal nodes in ZIFs suffers from an adverse electronic structure for oxygen electrocatalysis, as $\mathrm{Zn}$ and Co generally coordinate with four $\mathrm{N}$ from four dimethyl imidazole to form tetrahedral coordination $\left(T_{d}\right)$ in $\mathrm{ZIFs}^{35}$. Following the Sabatier principle, these $\mathrm{Zn}$ or Co nodes present a completely filled or half-empty $d$-orbitals, which results in bonding with oxygenated intermediates that are either too weak or too strong 36 . Currently, to develop pristine ZIFs for ZABs remains a major challenge, let alone the comprehensive studies on modulating electronic states of metal nodes to profoundly improve battery performance.

In this work, we propose a competing coordination strategy to prepare an air cathode based on vacancy-rich and hierarchically porous Co-Zn heterometallic ZIFs grown on Ni foam. The direct growth of ZIFs on Ni foam and its hierarchical porosity ensure rapid charge and mass transfer. Moreover, this strategy enables the regulation of ligand coordination and generation of unoccupied $3 d$-orbitals at metal sites to ease the energy barrier of oxygen electrocatalysis. Meanwhile, increment in $d$-orbital energy level via $\mathrm{Co}-\mathrm{Zn}$ heterometallic alliance further improves the intrinsic activity of active sites, as evidenced by the optimal electrocatalytic performance of $\mathrm{BHZ}-48$.

\section{Results}

Physicochemical characterizations. As the precursor, pristine Zn-based ZIFs arrays with average lateral length of three micrometers were grown on $\mathrm{Ni}$ foam (referred as $\mathrm{ZnMZ}$ ) through a low-temperature solvothermal reaction (Supplementary Fig. 1a, e and 2). The crystal framework of $\mathrm{ZnMZ}$ is assembled by $\mathrm{Zn}{ }^{\mathrm{II}}$ ions and dimethyl imidazole (DI) in the form of $\left[\mathrm{ZnN}_{4}\right]$ tetrahedrallike geometry, where $\mathrm{Zn}^{\mathrm{II}}$ ions are fully coordinated with the DI ligands via four $\mathrm{N}$ atoms (Fig. 1a) ${ }^{20}$. These quasi tetrahedra are then further edge/corner connected with each other to afford a two-dimensional structure ${ }^{20}$.

To synthesize heterometallic ZIFs with hierarchical pores and ligand vacancies $\left(V_{\mathrm{L}}\right)$, the pristine $\mathrm{ZnMZ}$ arrays were subjected to a cation-substitution treatment with $\mathrm{Co}^{\mathrm{II}}$ source for varying time lengths. A series of samples were obtained and named as BHZ-12, BHZ-24, BHZ-48, and BHZ-96, in which the numbers denote the substitution time in hours (Supplementary Fig. 1b-d, f-h). Scanning electron microscopy (SEM) and transmission electron microscopy (TEM) images unveil the morphology transformation from smooth arrays in $\mathrm{ZnMZ}$ to rough microsheets with a surface layer of partially exfoliated nanosheets (Fig. 1b, c and Supplementary Fig. 1). The high-angle annular dark-field scanning transmission electron microscopy image and corresponding electron energy loss spectroscopic (HAAD-EELS) elemental mappings show homogeneous elemental distribution throughout the nanosheets (Fig. 1d). Moreover, the ultrasonically broken fragment of BHZ-48 shows low imaging contrast and Tyndall light scattering, which confirm their ultrathin nature and colloidal dispersibility (Fig. 1e, f) ${ }^{37}$. According to the atomic force microscopy (AFM) image (Fig. 1f), the thickness of the nanosheet in BHZ-48 is $5.6 \mathrm{~nm}$. This is further proven in their crosssectional high-resolution TEM (HRTEM) image shown in inset of Fig. 1g. Unfortunately, due to rapid degradation of ZIFs under electron irradiation, visualization of their lattice fringes by HRTEM was not successful ${ }^{38}$. Interestingly, the emergence of uniform mesopores with width of $\sim 5 \mathrm{~nm}$ is detected in BHZ-48 (Fig. 1g), but is absent in ZnMZ (Supplementary Fig. 3). The coexistence of mesopores and intrinsic micropores in BHZ-48 is further confirmed by $\mathrm{N}_{2}$ isotherms with a type-IV hysteresis loops (Fig. 1h, i and Supplementary Table 1). According to previous reports, micropores with potential to host active sites contribute most of the catalytic activity, and mesopores are required to transport the reactant and product efficiently toward and away from the catalytic sites in the micropores ${ }^{39-41}$. Thus, such hierarchical pore structures of $\mathrm{BHZ}-48$ are favorable for propelling the oxygen electrocatalysis. Similarly, both BHZ-24 and BHZ-96 manifest hierarchical porosity (Supplementary Fig. 4). In contrast, the absence of hysteresis loop in ZnMZ isotherms clearly demonstrates its micropore dominant nature. It should be pointed out that such hierarchical porosity cannot be achieved via one-pot synthesis of Co-Zn bimetallic ZIFs (denoted as BMZ) using the same stoichiometric ratio of $\mathrm{Zn}\left(\mathrm{NO}_{3}\right)_{2}$, Co $\left(\mathrm{NO}_{3}\right)_{2}$ and DI, as smooth and thick nanosheets are generated instead (Supplementary Fig. 5). The key to the successful introduction of mesopores lies in the selected substitution process. During which, the acidic environment created by $\mathrm{Co}^{\mathrm{II}}$ hydrolysis gradually cleaves the $\mathrm{Zn}-\mathrm{N}$ coordination bonds, allowing the $\mathrm{Co}^{\mathrm{II}}$ to coordinate with the released DI and join into the ZnMZ framework ${ }^{42,43}$. The $\mathrm{Co}^{\mathrm{II}}$ presents half-empty $d$ orbital occupation, which gives rise to much stronger coordination capability than $\mathrm{Zn}$ II. As a consequence, equilibria is perturbed by competing DI coordination between Co and $\mathrm{Zn}$ 
a
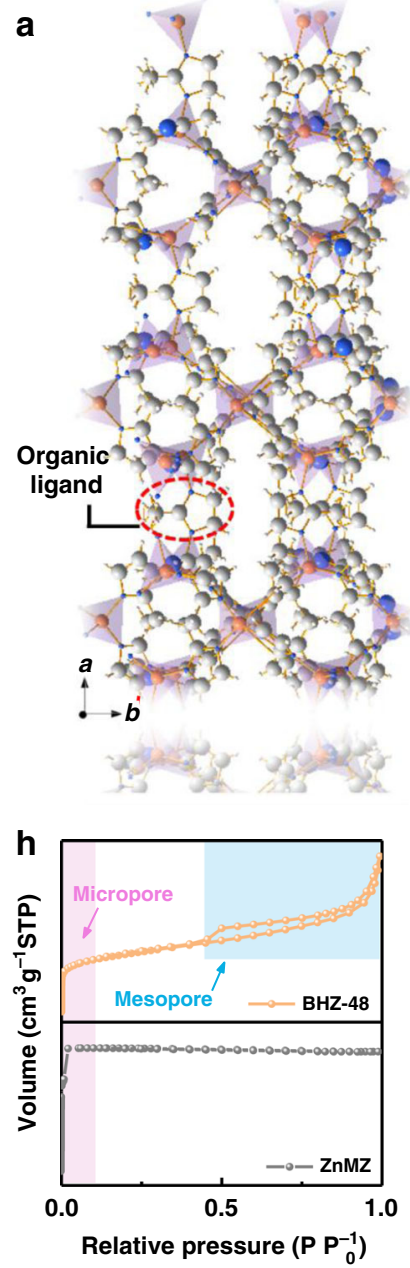
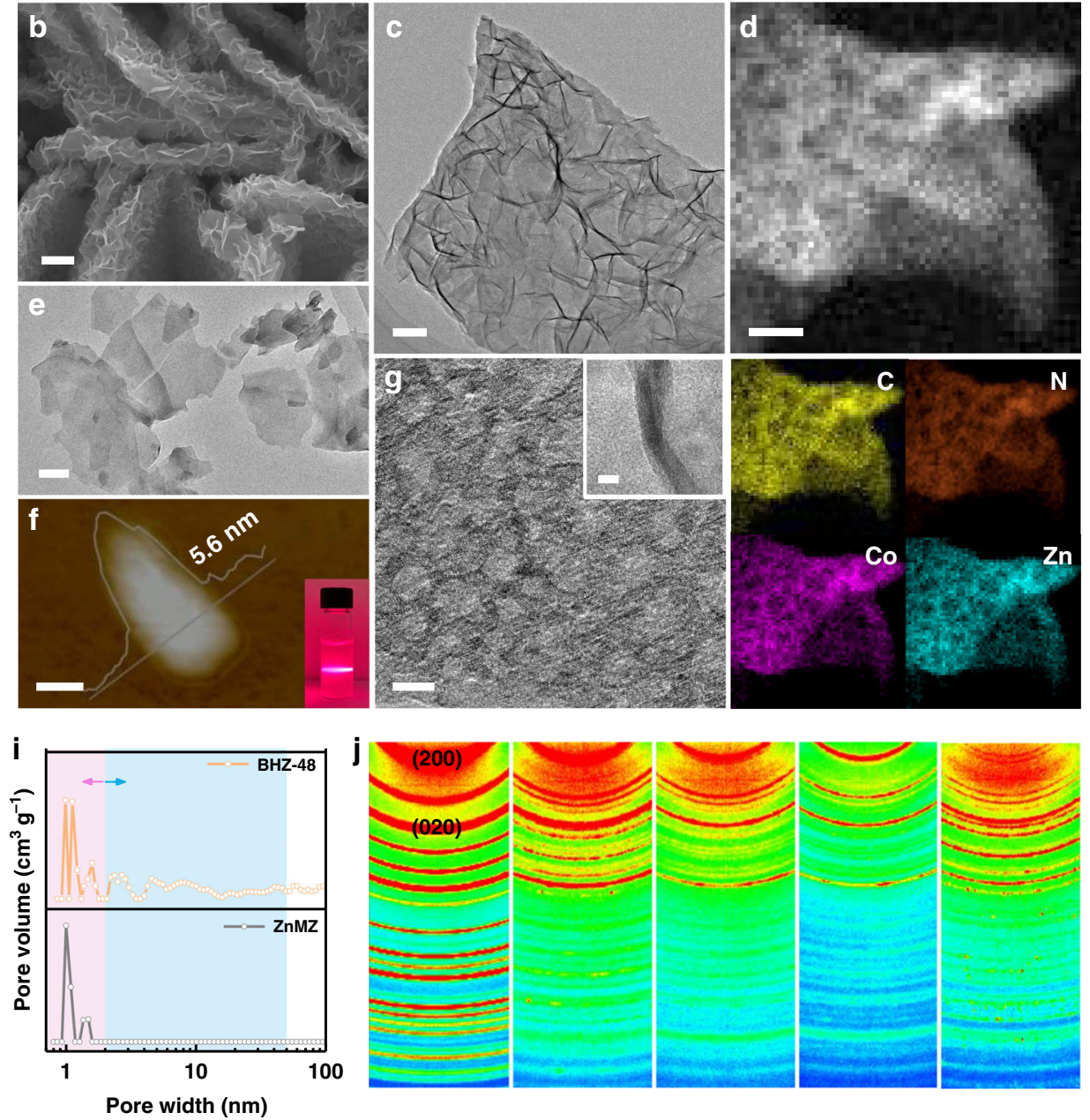

Fig. 1 Morphology and structural properties. a Schematic of the crystal structure of ZnMZ. b SEM and c TEM images of BHZ-48. d Scanning TEM images and corresponding EELS elemental maps of C, N, Co, and Zn atoms. e TEM, f AFM images and corresponding height curves of ultrasonically detached fragment from BHZ-48. Inset: Tyndall light scattering of $\mathrm{BHZ}-48$ nanosheets dispersed in aqueous solution. $\mathbf{g}$ High-resolution TEM image of $\mathrm{BHZ}-48$. $\mathbf{h} \mathrm{N}_{2}$ adsorption-desorption isotherms, i pore-size distribution of ZnMZ and BHZ-48. j Two-dimensional WAXS patterns of BHZ-48 and comparison samples, red color represents region with higher diffraction intensity. Scale bars: $1 \mu \mathrm{m}(\mathbf{b}), 200 \mathrm{~nm}(\mathbf{c}), 10 \mathrm{~nm}(\mathbf{d}), 100 \mathrm{~nm}(\mathbf{e}), 50 \mathrm{~nm}(\mathbf{f}), 5 \mathrm{~nm}(\mathbf{g}$ and inset of (g)).

sites, leading to mismatched crystal growth and the formation of defect-induced mesopore ${ }^{44}$.

Wide-angle X-ray scattering (WAXS) technique is carried out to investigate the crystallographic features of the materials. As shown in Fig. $1 \mathrm{j}$ and Supplementary Fig. 6a, these samples exhibit similar crystal structure with ZnMZ, which is in good agreement with the lamellar $\mathrm{ZIFs}^{20}$. Comparatively, as the cationsubstitution time increases, gradual lattice expansion is reflected by the left shift of diffraction peaks in BHZ-12, BHZ-24, and BHZ-48 (Supplementary Fig. 6b), which is consistent with the powder X-ray diffraction result (Supplementary Fig. 7). Moreover, the significant decrease in diffraction intensity of BHZ-48 reveals reduction in long-range order after the cation-substitution treatment, which originates from defect generation in the abovementioned competing coordination process (Fig. 1j and Supplementary Fig. 8$)^{45}$. Specifically, the $\mathrm{Zn}$ and Co ions dynamically compete for the ligand sites, thus re-coordination of $\mathrm{Co}$ and cleavage of $\mathrm{Zn}$ coordination bond can both occur during the process. As such, defect $\left(V_{\mathrm{L}}\right)$ can be generated on both Co and $\mathrm{Zn}$ sites within $\mathrm{BHZ}$ that are in the intermediate equilibrium states. The presence of defects are validated by spikes of the peak at $g=$ 2 in electron-paramagnetic resonance (EPR) spectra that is commonly associated with unpaired electrons (Fig. 2a) ${ }^{17}$.
The $V_{\mathrm{L}}$ influence on the chemical composition and coordination condition of ZIFs is investigated by X-ray photoelectron spectroscopy (XPS) and X-ray absorption spectroscopy (XAS). The simultaneous decreases of $\mathrm{C}$ and $\mathrm{N}$ contents suggest the gradual release of DI ligands in BHZ-12, BHZ-24, and BHZ-48 (Fig. 2b and Supplementary Fig. 9). As for BHZ-96, its C and N content recovers to a similar level as pristine $\mathrm{ZnMZ}$, which are in good agreement with the elemental analysis (EA) results (Supplementary Table 2). The variations in the number of $\mathrm{N}$ coordinated to central Co sites are supported by fitted Co $2 p_{3 / 2}$ XPS spectra (Fig. 2c). The peak at $781.1 \mathrm{eV}$ is attributed to fully coordinated $\mathrm{Co}$ in a Co- $\mathrm{N}_{4}$ environment, and the peak at 779.9 $\mathrm{eV}$ is assigned to unsaturated cobalt species in Co- $\mathrm{N}_{x}(x<4)$ geometry. The Co- $\mathrm{N}_{x}$ to Co- $\mathrm{N}_{4}$ peak intensity ratio experiences a clear increase from $\mathrm{BHZ}-12$ to $\mathrm{BHZ}-48$, indicating reduced $\mathrm{Co}-\mathrm{N}$ coordination number. Then, cobalt species in unsaturated geometry $\left(\mathrm{Co}-\mathrm{N}_{x}\right)$ decreases from $57.1 \%$ in $\mathrm{BHZ}-48$ to $16.6 \%$ in BHZ-96. Considering their similar Co contents by inductively coupled plasma atomic emission spectroscopy (ICP-AES), the composition difference is ascribed to re-coordination of DI ligands at unsaturated orbitals of Co sites (Supplementary Table 2). High-resolution Co $2 p$ XPS spectra of samples obtained in a substitution treatment with $\mathrm{Co}^{\mathrm{II}}$ source for 60,72 , and $84 \mathrm{~h}$ 
a
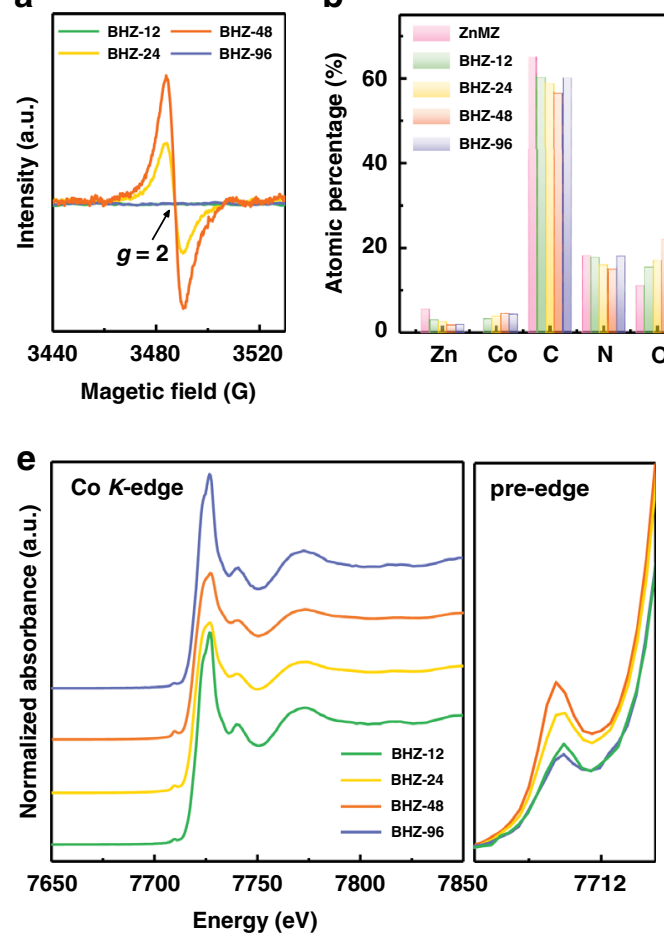

C
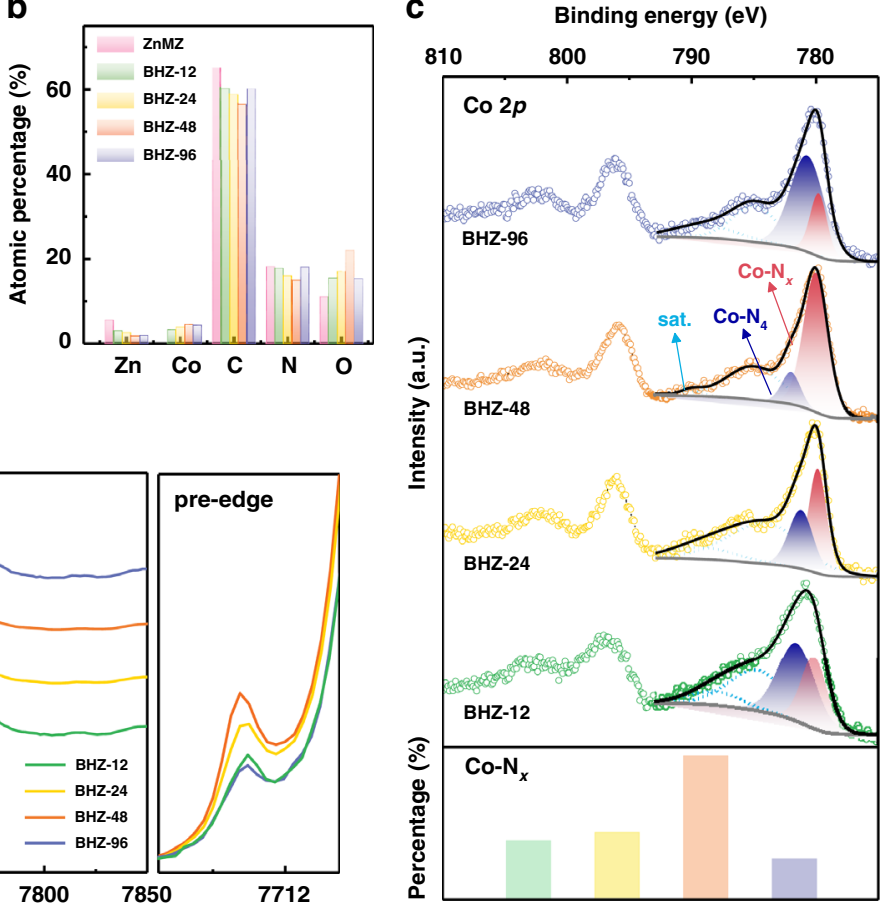

d
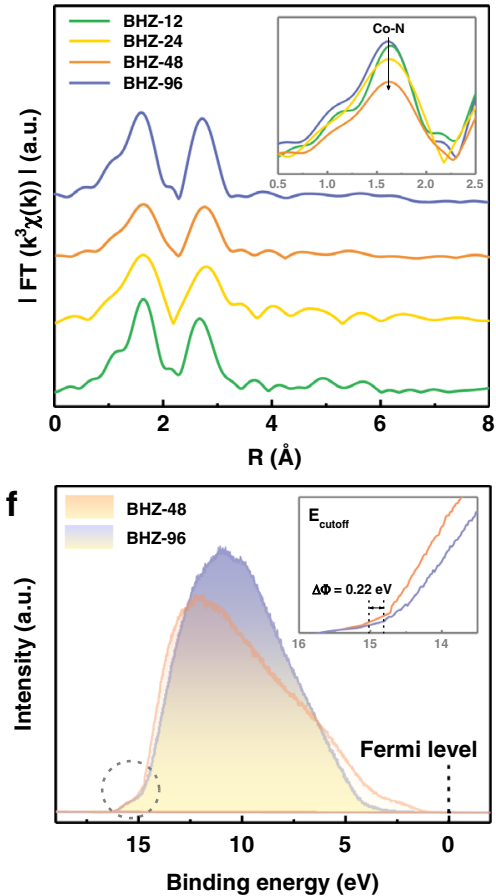

Fig. 2 Chemical composition, electronic state, and coordination environment. a Electron-paramagnetic resonance spectra, $\mathbf{b}$ XPS derived element contents, $\mathbf{c}$ high-resolution Co $2 p$ XPS spectra, $\mathbf{d}$ R-space Co K-edge EXAFS spectra, and $\mathbf{e}$ Co $K$-edge XANES spectra as well as the amplified pre-edges of samples in the $\mathrm{BHZ}$ series. $\mathbf{f}$ UPS spectra of $\mathrm{BHZ}-48$ and $\mathrm{BHZ}-96$ collected using an $\mathrm{He} \mathrm{I}(21.2 \mathrm{eV})$ radiation. Inset: enlarged view of the secondary electron tail threshold.

(denoted as BHZ-60, BHZ-72, and BHZ-84) further reveal the recoordination phenomena (Supplementary Fig. 10). The vanished EPR signal of BHZ-96 also validates defect removal due to recoordination and reversion from metal- $\mathrm{N}_{\mathrm{x}}$ to saturated metal- $\mathrm{N}_{4}$ geometry (Fig. 2a). In order to verify the transformation, k-space and Fourier transform (FT) R-space of extended X-ray absorption fine structure (EXAFS) spectra are further analyzed to investigate the Co coordination condition. As demonstrated in Fig. $2 \mathrm{~d}$ and Supplementary Fig. 11, despite having similar type of Co-N and Co-C coordination shells, BHZ-48 presents the lowest Co-N peak intensity, implying minimal Co-N coordination number. Fitting result of Co-N peak shows an average bond length of $\sim 2.10 \AA$, while the corresponding coordination number is 2.9 for $\mathrm{BHZ}-48$ and 4.3 for BHZ-96 (Supplementary Table 3). In Co K-edge $\mathrm{k}^{3} \chi$ (k) spectra (Supplementary Fig. 12), BHZ-48 exhibits lower oscillation amplitude than BHZ-96, suggesting more disordered local atomic arrangements in the presence of $V_{\mathrm{L}}$, in consistent with the decrease in WAXS intensity observed on $\mathrm{BHZ}-48^{46}$. Similar results are also obtained in Zn $K$-edge EXAFS spectra and corresponding FT curves (Supplementary Fig. 13). The coordination environment of Co center with $T_{d}$ symmetry is further discerned by the $1 s \rightarrow 3 d$ transition pre-edge shoulder at $\sim 7709$ $\mathrm{eV}$ in Co K-edge X-ray absorption near edge structure (XANES, Fig. 2e $)^{17}$. The overall XANES spectral shapes of the four samples are similar, with subtle changes observed in pre-edge positions. Given that the pre-edge structure is an indicator of $d$-orbital occupancy ${ }^{47}$, the highest pre-edge peak of BHZ-48 confirms its lowest $d$-orbital occupancy along with increased $V_{\mathrm{L}}$ abundancy (inset of Fig. 2e). The difference in $d$-orbital occupancy may contribute to distinct work function $(\Phi)$ with altered band positions relative to vacuum. This is clearly reflected by ultraviolet photoemission spectroscopy (UPS) spectra, in which the smaller $\Phi$ of BHZ-48 $(6.18 \mathrm{eV})$ compare to BHZ-96 $(6.40 \mathrm{eV})$ suggests lower energetic barrier for transferring electrons between active sites and adsorbed intermediates (Fig. $2 \mathrm{f})^{48,49}$. Base on the above results, the $V_{\mathrm{L}}$ formation and decreased occupancy of Co $d$ orbital states are evidenced to promote electron injection/ extraction in $\mathrm{O}^{2-} / \mathrm{OH}^{-}$redox and hence accelerates the reaction kinetics.

Electrochemical behaviors. Subsequently, the oxygen electrocatalytic activities of the synthesized ZIFs as working electrodes are evaluated in a three-electrode system with $0.1 \mathrm{M} \mathrm{KOH}$ as electrolyte. Commercial $\mathrm{RuO}_{2}$ powder loaded on $\mathrm{Ni}$ foam was prepared as the OER performance benchmark. As illustrated in Fig. 3a, BHZ-48 displays high activity, achieving the lowest overpotential $(170 \mathrm{mV})$ at the current density of $50 \mathrm{~mA} \mathrm{~cm}^{-2}$ $\left(E_{j=50}\right)$ among all samples. It is worth to mention that minimal anodic current density is measured from bare $\mathrm{Ni}$ foam when compared to the catalyst-grown counterparts (Supplementary Fig. 14), which suggest that the high OER activity is solely contributed by the ZIFs catalysts. The relationship between $V_{\mathrm{L}}$ and OER activity is also revealed in the comparison between BHZ-48 and BHZ-96. At a low overpotential of $260 \mathrm{mV}, \mathrm{BHZ}-48$ achieves a current density of $400 \mathrm{~mA} \mathrm{~cm}^{-2}$, which is approximately three times higher than the $125 \mathrm{~mA} \mathrm{~cm}^{-2}$ of $\mathrm{BHZ}-96$, suggesting correlation between unsaturated coordination and improved activity. The smallest Tafel slope of BHZ-48 $\left(80 \mathrm{mV} \mathrm{dec}^{-1}\right)$ also indicates the highest reaction kinetics (Fig. 3b).

As for ORR performance, linear sweep voltammetry (LSV) is employed to evaluate the as-synthesized ZIFs with commercial $\mathrm{Pt} / \mathrm{C}$ as performance benchmark (Fig. 3c). BHZ-48 surpasses others with onset potential $\left(E_{\text {onset }}\right)$ of $0.90 \mathrm{~V}$, half-wave potential ( $E_{\text {half-wave }}$ ) of $0.84 \mathrm{~V}$, as well as limiting current of $-4.60 \mathrm{~mA} \mathrm{~cm}^{-2}$ (Supplementary Table 4). To further confirm the electrocatalytic kinetics of BHZ-48, LSV curves at different rotating speeds were collected and corresponding Koutecky-Levich (K-L) plots were 

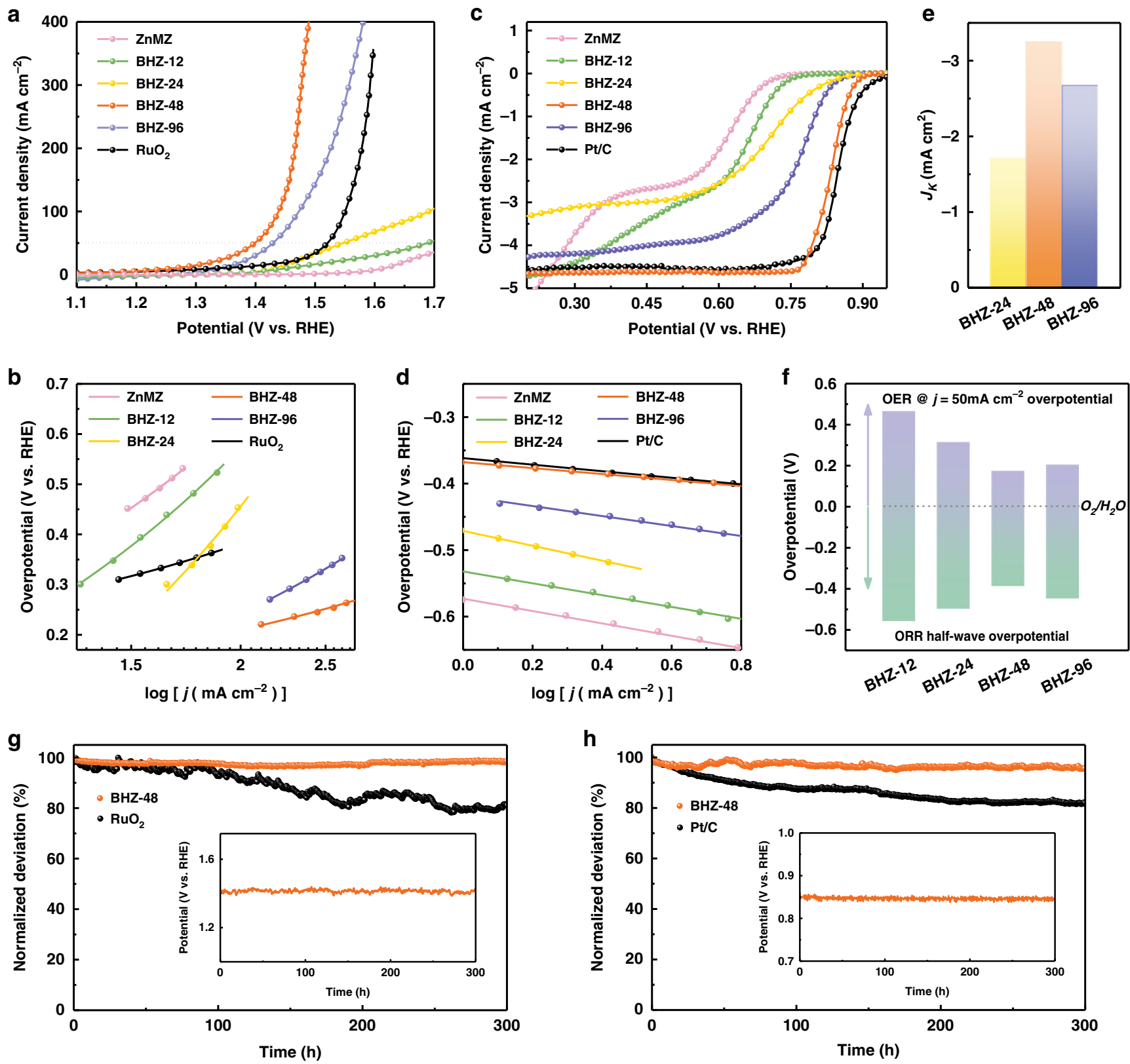

Fig. 3 Electrochemical behaviors in half-cell. a OER LSV curves, b OER Tafel plots comparison, c ORR LSV curves, d ORR Tafel plots comparison of samples in the $\mathrm{BHZ}$ series, commercial $\mathrm{RuO}_{2}$, and $\mathrm{Pt} / \mathrm{C}$. e Comparison of $J_{K} @$ half-wave potential, $\mathbf{f}$ overpotential differences between the $E_{\text {half-wave }}$ of ORR and $E_{j=50}$ of OER for BHZ-48 and other products. $\mathbf{g}$ OER chronoamperometric response at a fixed overpotential of $170 \mathrm{mV}$ for $\mathrm{BHZ}-48$ and $290 \mathrm{mV}$ for $\mathrm{RuO}_{2}, \mathbf{h}$ ORR chronoamperometric response of $\mathrm{BHZ}-48$ and $\mathrm{Pt} / \mathrm{C}$ at a fixed potential of $0.7 \mathrm{~V}$ vs. RHE. Inset: chronopotentiometric response at a constant anodic and cathodic current density for BHZ-48.

analyzed (Supplementary Fig. 15), which indicates an apparent four-electron reduction from oxygen to $\mathrm{OH}^{-}$in BHZ-48. Among catalysts with analogous four-electron reduction, BHZ-48 exhibits the smallest Tafel slope and highest kinetic current density $\left(J_{K}\right)$, which further implies its most favorable ORR kinetics (Fig. 3d, e and Supplementary Table 5).

Such bifunctionality arises from the pore reformation and accelerated reactants transport. This is proven by larger electrochemically active surface area (ECSA) of BHZ-48, derived from the calculated electrochemical double-layer capacitance $\left(C_{\mathrm{dl}}\right.$ $=25.96 \mathrm{mF} \mathrm{cm}^{-2}$ ), which is 10 times higher than pristine $\mathrm{ZnMZ}$ of $2.50 \mathrm{mF} \mathrm{cm}^{-2}$ (Supplementary Fig. 16). The catalytic activities of these ZIFs are further normalized by their ECSA, to isolate and identify the enhancement in intrinsic activity from the unsaturated Co $d$-orbitals (Supplementary Fig. 17). Then, the differences $\left(\Delta E=E_{j=50}-E_{\text {half-wave }}\right)$ between OER potentials at $50 \mathrm{~mA} \mathrm{~cm}^{-2}\left(E_{j=50}\right)$ and ORR half-wave potentials ( $\left.E_{\text {half-wave }}\right)$ are calculated to directly elucidate the bifunctional activity as compared in Fig. 3f. As shown, BHZ-48 exhibits the smallest $\Delta E$ of $0.56 \mathrm{~V}$, which outperforms all counterparts and also welldeveloped electrocatalysts in literatures $9,11,42,50,51$.

Additionally, electrochemical analyses of various protocols are carried out to comprehensively evaluate the stability of BHZ-48. In Fig. 3g, BHZ-48 demonstrates superior OER stability compared to $\mathrm{RuO}_{2}$ with only $3 \%$ activity loss after $300 \mathrm{~h}$ of continuous chronoamperometry tests, which is consistent with the steady activity trend in chronopotentiometry test. It was also found that BHZ-48 retains its OER activity with negligible 

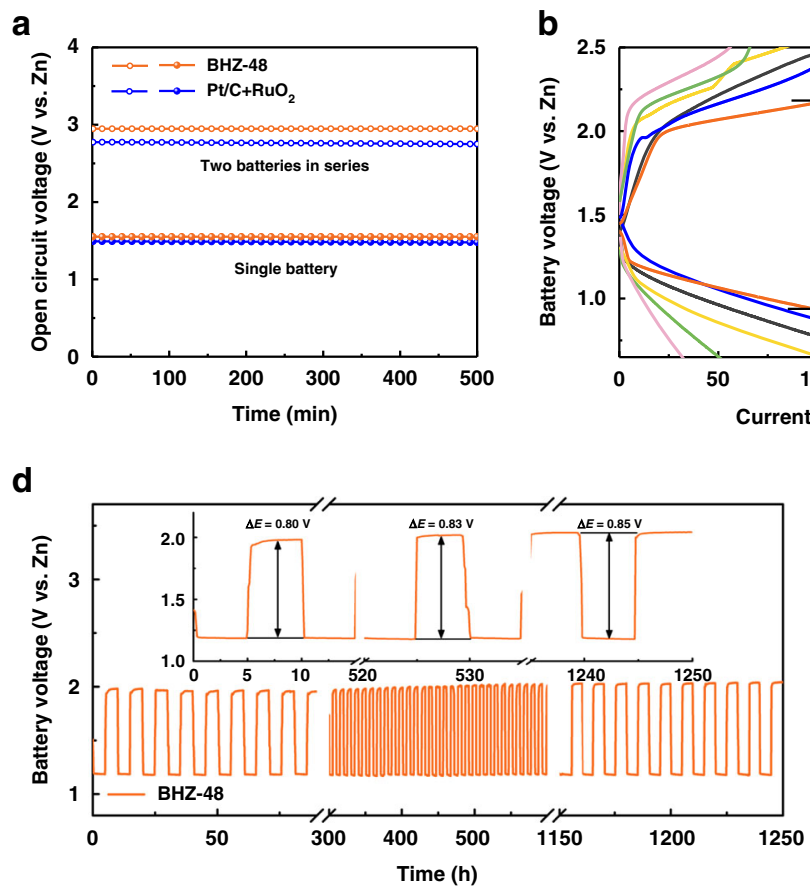
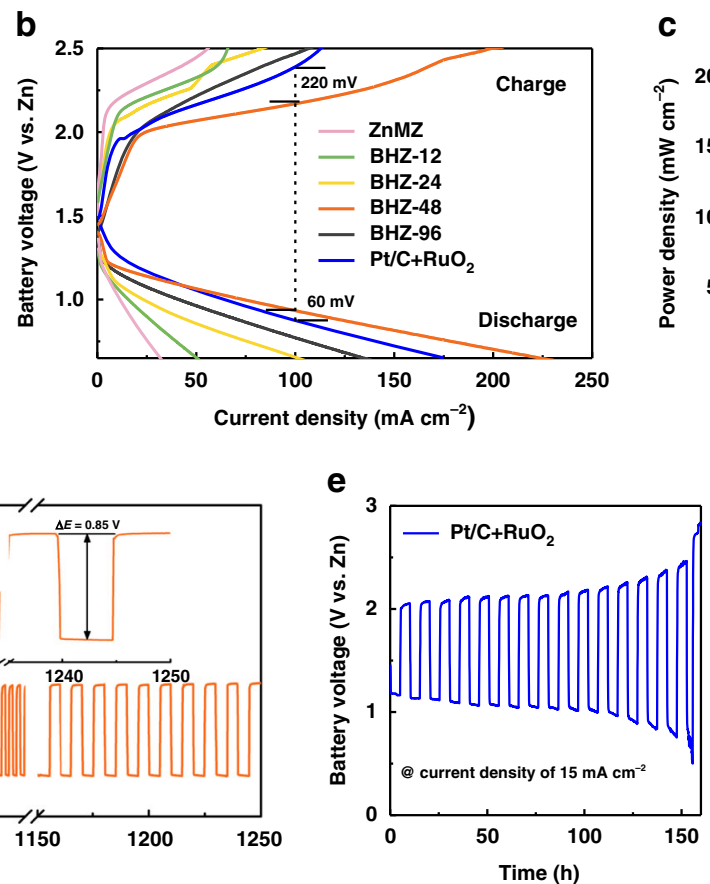
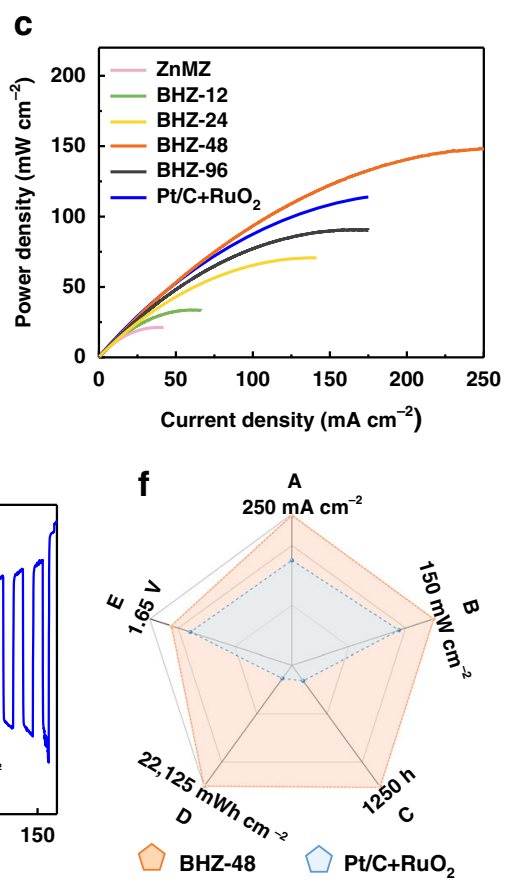
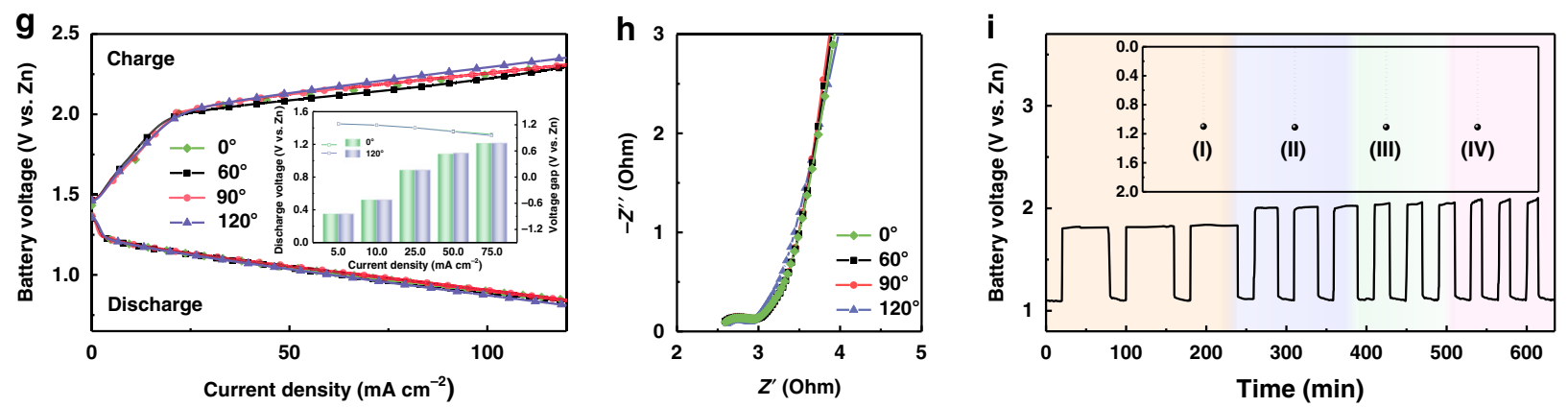

Fig. $4 \mathbf{Z n}$-air battery performance evaluation. a Open-circuit voltage curves, $\mathbf{b}$ charge and discharge polarization curves, and $\mathbf{c}$ corresponding power density plots for $\mathrm{Zn}$-air battery prepared with $\mathrm{BHZ}-48$ or Pt/C $+\mathrm{RuO}_{2}$ electrodes. d Galvanostatic cycling stability of $\mathrm{Zn}$-air battery prepared with $\mathrm{BHZ}-48$ electrode, and $\mathbf{e}$ the $\mathrm{Pt} / \mathrm{C}+\mathrm{RuO}_{2}$ electrode at a current density of $15 \mathrm{~mA} \mathrm{~cm}{ }^{-2}$. $\mathbf{f}$ Comparison of key performance parameters for $\mathrm{BHZ}-48$ and $\mathrm{Pt} / \mathrm{C}+$ $\mathrm{RuO}_{2}$ electrodes. A: current density; B: power density; C: lifespan, D: cumulative energy density; E: discharge voltage. $\mathbf{g}$ Charge and discharge polarization curves, inset: corresponding discharge voltages and voltage gaps. $\mathbf{h}$ Nyquist plots of the flexible $\mathrm{Zn}$-air battery prepared using the $\mathrm{BHZ}-48$ electrode under different bending angles. i Alternating charging mode test, (I) $10 \mathrm{~mA} \mathrm{~cm}^{-2}, 60 \mathrm{~min}$, (II) $20 \mathrm{~mA} \mathrm{~cm}^{-2}, 30 \mathrm{~min}$, (III) $30 \mathrm{~mA} \mathrm{~cm}-2,20 \mathrm{~min}$, (IV) $40 \mathrm{~mA} \mathrm{~cm}$, , $15 \mathrm{~min}$. Inset in i: average discharging voltage variation.

decrease in $E_{j=50}(171 \mathrm{mV})$ after 3000 cycles of cyclic voltammetry $(\mathrm{CV})$ scans, while $\mathrm{RuO}_{2}$ catalyst experience an increase from 290 to $300 \mathrm{mV}$ (Supplementary Fig. 18a). As for the ORR performance, despite having activity slightly inferior to $\mathrm{Pt} /$ C, BHZ-48 achieves a near $100 \%$ retention that is superior to $80 \%$ of Pt/C (Fig. 3h). Three-hundred hours of continuous electrocatalysis at constant current also brings negligible decay in potential (inset of Fig. 3h). The durability of BHZ-48 is further confirmed in CV tests without detectable activity loss after 3000 CV cycles (Supplementary Fig. 18b), which should be ascribed to its stable structure and morphology as evidenced by post-cycling characterizations in Supplementary Figs. 19 and 20.

Next, BHZ-48 is directly applied as the air cathode in ZABs. The open-circuit voltage of BHZ-48 is $1.49 \mathrm{~V}$ (vs. $\mathrm{Zn}$ ) and $2.95 \mathrm{~V}$ in series, which are higher than the values of commercial $\mathrm{Pt} / \mathrm{C}+$ $\mathrm{RuO}_{2}$ reference $(1.44 \mathrm{~V}$ and $2.77 \mathrm{~V}$, Fig. $4 \mathrm{a})$. This result aligns well with the lower internal resistance of BHZ-48 (1.6 $\Omega$ ) measured in electrochemical impedance spectroscopy (EIS, Supplementary Fig. 21a). Figure $4 \mathrm{~b}$ compares the charge and discharge polarization curves of different electrodes. Among them, BHZ-48 exhibits the narrowest voltage-gap and highest power density of $148 \mathrm{~mW} \mathrm{~cm}^{-2}$ at $250 \mathrm{~mA} \mathrm{~cm}^{-2}$. This maximal power density also outperforms $113 \mathrm{~mW} \mathrm{~cm}^{-2}$ of $\mathrm{Pt} / \mathrm{C}+\mathrm{RuO}_{2}$ (Fig. 4c). The cyclability in ZABs was tested by galvanostatic discharge-charge method at a current density of $15 \mathrm{~mA} \mathrm{~cm}^{-2}$. As shown in Fig. 4d, ZABs with BHZ-48 delivers an initial potential of $1.18 \mathrm{~V}$ for discharge and $1.98 \mathrm{~V}$ for charge, respectively. After $1250 \mathrm{~h}$ of operation, the voltage-gap increases by only $0.05 \mathrm{~V}$, which converts to an low fading rate of $0.004 \%$ per hour (Supplementary Fig. 21b). As for the $\mathrm{Pt} / \mathrm{C}+\mathrm{RuO}_{2}$ reference, it shows rapid voltage-gap expansion from $0.87 \mathrm{~V}$ to $1.63 \mathrm{~V}$ after $150 \mathrm{~h}$ with a fading rate of $0.51 \%$ per hour, which is two orders of magnitude faster than BHZ-48 (Fig. 4e). The robust corrosion resistance of BHZ-48 is further evident by its obviously lighter electrolyte color than commercial $\mathrm{Pt} / \mathrm{C}+\mathrm{RuO}_{2}$ after cycling (Supplementary Fig. 21c). Overall, this air electrode outperforms commercial noble metals in key aspects (Fig. 4f), and is also comparable to or even better than most reported ZABs to date (Supplementary Table 6).

To explore the feasibility of BHZ-48 in practical application, a flexible ZAB is assembled as shown in Supplementary Fig. 22. 
Figure $4 \mathrm{~g}$ and Supplementary Fig. 23 present its output voltage and power density as a function of current density under various bending angles. The voltage polarization of this battery remains virtually unchanged at a high current density of $120 \mathrm{~mA} \mathrm{~cm}^{-2}$ for both charge and discharge. Particularly, negligible increase is detected at $120^{\circ}$ and a maximum power density of $100 \mathrm{~mW} \mathrm{~cm}^{-2}$ is achieved. Additionally, EIS results of the battery assembled with BHZ-48 are presented in Fig. 4h. The closely overlapping semicircle and tail in Nyquist plots suggest similar charge transfer and interfacial resistances in different bending conditions. Another desired property for rechargeable batteries is fastcharging capability, but it remains a huge challenge to achieve without negative influence on battery performance ${ }^{52,53}$. Given so, flexible ZAB with $\mathrm{BHZ}-48$ electrode was tested under alternating charging mode (slow, even, fast). As depicted in Fig. 4i, both of its discharging voltage and the capacity are maintained, and the remarkable reversibility is showcased. These features demonstrate the robust physical stability, decent rechargeability, and conductivity of the BHZ-48 electrode, conferring its great promise in practical application.

Mechanistic study. To decipher the underlying relevance of $V_{\mathrm{L}}$ on the material electrochemical behaviors, spectroscopic measurements and theoretical modeling of the two half reactions at air cathode are conducted. Three-coordinated BHZ-48 and fourcoordinated BHZ-96 were processed to different potentials and investigated by EXAFS. As shown in Fig. 5, Co K-edges of BHZ48 and BHZ-96 both shift to higher energy with increasing potential during OER, suggesting elevation in average oxidation associated with deprotonation of bridged $\mathrm{OH}^{*}$ and $\mathrm{OOH}^{*}$ on $\mathrm{Co}$ sites. The edge shift in BHZ-48 is larger than BHZ-96 within the same potential window, indicating better proton extraction from oxygen intermediates due to the presence of $V_{\mathrm{L}}$. When processed back to the open-circuit voltage, both energy and Co-N coordination condition show insignificant differences with pristine electrocatalysts, implying high reversibility of the deprotonation reaction in both BHZ-48 and BHZ-96. This can be explained by the self-healing feature of MOFs, which allows unrestricted DI ligands to substitute bridged $\mathrm{OH}^{-}$, followed by the recovery of $\mathrm{Co}$ coordination configurations of BHZ-48 and BHZ-96 to their pristine state ${ }^{54}$. Then, free-energy diagrams of the reaction mechanism are modeled based on density functional theory (DFT) to validate the correlation between the coordination structure of metal nodes and OER activity. As shown in Fig. 6a, the OER pathway involves four protons/electrons transferred steps and three intermediates of ${ }^{*} \mathrm{OH},{ }^{*} \mathrm{O}$, and ${ }^{*} \mathrm{OOH}$. In an ideal catalyst, the adsorption energy barrier is $2.46 \mathrm{eV}$ for ${ }^{*} \mathrm{OH}$ to $* \mathrm{OOH}$ transformation $\left(\Delta E_{d}=\Delta G^{*} \mathrm{OH}-\Delta G * \mathrm{OOH}\right)^{55}$. As shown in Fig. $6 \mathrm{~b}$, it is clear that $\mathrm{BHZ}-48$ is closer to this value compared to BHZ-96. The Gibbs free energy difference between BHZ-48 and BHZ-96 lead to different potential-determining step (PDS) of OER. The PDS for BHZ-96 is $* \mathrm{OOH}$ deprotonation into $\mathrm{O}_{2}$ molecule that requires a reaction free-energy barrier of $2.05 \mathrm{eV}$, whereas that for $\mathrm{BHZ}-48$ is ${ }^{*} \mathrm{OH}$ deprotonation with a readily surmountable energy barrier of $1.75 \mathrm{eV}$ (Fig. $6 \mathrm{c}$ and Supplementary Fig. 24). Consequently, the reduced PDS energy barrier accelerates the OER kinetics of BHZ-48, resulting in a $30 \mathrm{mV}$ lower theoretical OER overpotential $\left(\eta_{O E R}^{t}\right)$ than BHZ-96 (Fig. 6c). Furthermore, the electrochemical activation energies are extracted from OER Arrhenius plots and assessed to further corroborate that the $V_{\mathrm{L}}$ is a critical factor for intrinsic activity improvement (Supplementary Fig. 25). Comparatively, BHZ-48 exhibits a much smaller apparent barrier value of $12.2 \mathrm{~kJ} \mathrm{~mol}^{-1}$ than BHZ-96 $\left(17.6 \mathrm{~kJ} \mathrm{~mol}^{-1}\right)$, which aligns well with DFT simulations.
The influence of electronic state variations caused by Co- Zn alliance on ORR activity is also investigated by free-energy diagrams (Fig. 6d). In this case, the heterometallic BHZ-48 was compared with monometallic Zn ZIF and Co ZIF (denoted as $\mathrm{ZnHZ}$, CoHZ, respectively). For $\mathrm{ZnHZ}$, the initial oxygen activation step (transformation of $\mathrm{O}_{2}$ to ${ }^{*} \mathrm{OOH}$ ) is the PDS owing to the weak interaction between active center and adsorbates. In comparison, $\mathrm{CoHZ}$ and $\mathrm{BHZ}-48$ both encounter relatively low resistance during the oxygen activation step, and hence ${ }^{*} \mathrm{OH}$ desorption with large energy barriers is their PDS (Fig. 6d). Between the two, BHZ-48 exhibits lower $\mathrm{OH}^{*}$ adsorption energy resulting in eased $\mathrm{OH}^{-}$release (Supplementary Fig. 26). This trend follows the Sabatier principle, i.e., insufficient adsorption energy is adverse to progression of the subsequent reactions, while excessive adsorption would lead to difficulty in product desorption $^{56}$. For an intuitive comparison, ORR overpotential $\left(\eta_{O R R}^{t}\right)$ on each catalytic site was further calculated under the thermodynamic equilibrium potential of ORR at $U=$ $1.23 \mathrm{~V}$ (Supplementary Fig. 27). The lowest $\eta_{O R R}^{t}$ is obtained in BHZ-48, which is due to its optimal adsorption/desorption behaviors established by fine-tuning of the electronic structure. Further insights are gained by examining the metal centers density of states (DOS), as the $d$ band center $\left(\varepsilon_{d}\right)$ is highly correlated with the metal-adsorbate interaction. As shown in Fig. $6 \mathrm{e}$ and $\mathrm{f}$, the upshift of $\varepsilon_{d}$ is observed in BHZ-48 compared to $\mathrm{ZnHZ}$, reflecting the positive influence of Co- $\mathrm{Zn}$ heterometallic alliance. The explanation for the coupling phenomenon is demonstrated using their electronic structure in Fig. 6g. Specifically, the valence electron configuration of $\mathrm{Zn}^{\mathrm{II}}$ is $3 d^{10}$ with fully occupied $d$-orbitals in the $\pi$-symmetry $t_{2}\left(d_{\mathrm{xy}}\right.$, xz, yz $)$ orbitals ${ }^{57}$. For this reason, electron repulsion is the dominating interaction between the bridging $\mathrm{N}$ and $\mathrm{Zn}$. In contrast, the $\pi$-symmetry orbitals of $\mathrm{Co}^{\mathrm{II}}$ in tetrahedral geometry with high-spin state are half-empty, which can interact with bridging $\mathrm{N}$ via $\pi$-donation. As a result, the cooperative effects within $\mathrm{Co}-\mathrm{Zn}$ alliance enhance the $\pi$-donation interaction of $\mathrm{Co}-\mathrm{N}$ by electron repulsion of $\mathrm{Zn}-\mathrm{N}$, promoting the partial charge transfer from $\mathrm{Zn}$ towards $\mathrm{Co}$, and lowering the energy level of Co $d$-orbitals ${ }^{37}$.

\section{Discussion}

At this point, the physicochemical and electrochemical properties of Co-Zn heterometallic ZIF has been characterized and analyzed. Their performance in ZABs is attributed to several critical factors that were endowed by its facile and versatile synthetic scenario. First, its hierarchical porosity introduced by the pyrolysis-avoided competing coordination strategy significantly relieves the electrolyte flooding issues that obstructs $\mathrm{O}_{2}$ diffusion in microporous ZIF, which has long been a major challenge associated with ZIFbased catalysts. The introduction of mesopores is caused by competing crystal growth between the original metal nodes with external cations in the substitution reaction. During which, although both $\mathrm{Zn}{ }^{\mathrm{II}}$ and $\mathrm{Co}^{\mathrm{II}}$ can coordinate with DI ligands into isostructural crystalline framework, $\mathrm{Zn}^{\mathrm{II}}$ with full $d$-orbital occupation has much weaker coordination capability than $\mathrm{Co}^{\mathrm{II}}$, which gives rise to new Co-N coordination matrix and mesopores. The synthetic method can be extended to ZIFs containing other metal nodes, e.g., $\mathrm{Fe}^{\mathrm{II}}, \mathrm{Ni}^{\mathrm{II}}$, and $\mathrm{Cu}^{\mathrm{II}}$, as indicated in Supplementary Fig. 28. The second efficacy of such strategy is the realization of controlled ligand editing and heteroatomic doping, which allows the generation of ligand vacancies and tuning of oxygen intermediates adsorption/desorption barriers to shift catalytic activity towards the vertex. These results establish an applicable direction to improve ZABs performance and other electrocatalysis systems by modulating ligand environment and heterometallic alliance. In addition, the self-healing feature of MOFs 

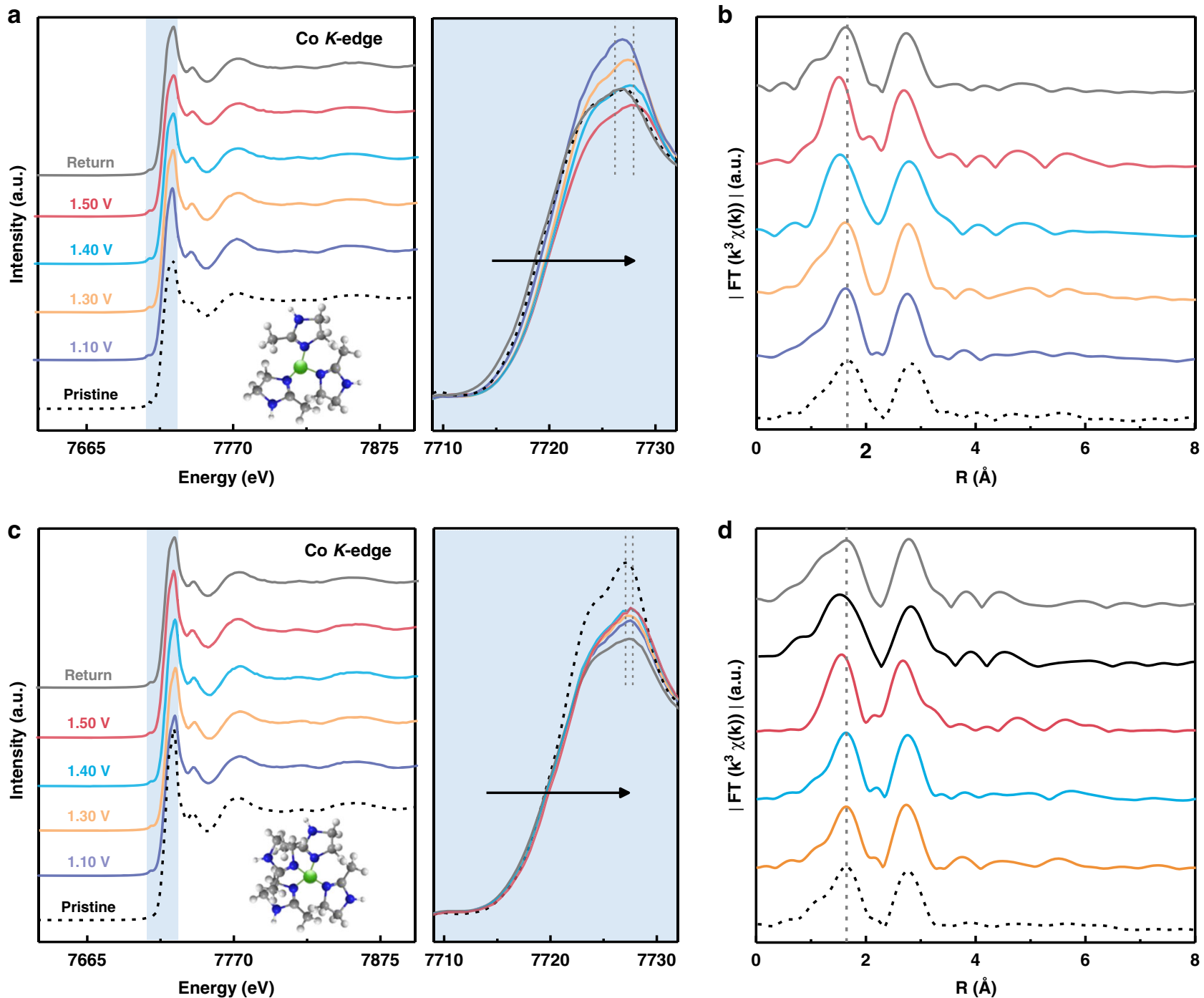

Fig. 5 X-ray absorption spectroscopic analysis. Co K-edge (a) XANES spectra and (b) EXAFS in R-space of as-prepared BHZ-48 collected during potentiostatic OER experiments at various potentials. Co K-edge (c) XANES spectra and (d) EXAFS in R-space of as-prepared BHZ-96 collected during potentiostatic OER experiments at various potentials.

is conducive to repairing metal-ligand coordination environment that alleviates performance degradation from active metal sites dissociation ${ }^{54}$. It differs from the irreversible evolution of metal compounds upon electrocatalytic process ${ }^{17}$. This behavior originates from the relatively weaker strength of coordination bonds $\left(<200 \mathrm{~kJ} \mathrm{~mol}^{-1}\right)$ than ionic or metallic bonds $\left(>700 \mathrm{~kJ} \mathrm{~mol}^{-1}\right)^{58,59}$. Lastly, the heterocyclic aromatic ligand of $\mathrm{BHZ}-48$ without unpaired electron can effectively suppress undesirable attack by free oxygen radicals, thereby promoting strong durability in battery cycling 27 .

In summary, a strategy to synchronously create hierarchical porosity and steer orbital state of metal nodes is designed for ZIFs. In the as-prepared BHZ-48, the orbital configuration of active sites is modulated by both the near-range interaction with ligand vacancies and the long-range interaction of $\mathrm{Co}-\mathrm{Zn}$ alliance. As a result, the adsorption/desorption energy of reactive intermediates achieves an optimal state, where the energy barrier for potential-determining step is significantly lowered. When BHZ48 is applied as air electrode in rechargeable ZABs, a charge-discharge voltage-gap of $0.8 \mathrm{~V}$ and a stable cyclability over $1250 \mathrm{~h}$ are achieved at $15 \mathrm{~mA} \mathrm{~cm}{ }^{-2}$. Based on these evidences and fundamental understandings, this study showcases not only a strategy to design a conceptually unique electrocatalyst in the vast collections of pristine MOFs, but also a direction to steer oxygen electrochemistry for heterogeneous catalysis and other electrochemical energy storage systems.

\section{Methods}

Materials. dimethyl imidazole (99\%, Analytical grade), zinc nitrite hexahydrate ( $99 \%$, Analytical grade), zinc acetate tetrahydrate (99\%, Analytical grade), cobalt nitrite hexahydrate (99\%, Analytical grade), potassium hydroxide (85\%, Analytical grade) and methanol (99.9\%, anhydrous) were purchased from Sigma-Aldrich. Nafion ${ }^{\mathrm{TM}}$ dispersion ( $5 \mathrm{wt} . \%$ in ethanol) was purchased from Ion Power. All chemicals were used without further purification. The deionized water $(18 \mathrm{M} \Omega)$ was obtained from a Millipore System.

Synthesis of $\mathbf{Z n M Z}$ electrode. In all, $0.40 \mathrm{mmol} \mathrm{Zn}\left(\mathrm{NO}_{3}\right)_{2} \cdot 6 \mathrm{H}_{2} \mathrm{O}$ was first dissolved in $40 \mathrm{ml}$ deionized water. The solution was then added to $40 \mathrm{ml}$ deionized water containing $0.53 \mathrm{mmol}$ dimethyl imidazole under ultrasonication. Subsequently, a piece of $\mathrm{Ni}$ foam (NF) was immersed into the mixed solution and transferred into a $100 \mathrm{ml}$ Teflon vessel, which is then placed at $60^{\circ} \mathrm{C}$ for $24 \mathrm{~h}$ under airtight conditions. After cooling to room temperature, the NF was obtained, washed by deionized water, and dried in ambient air. 
a

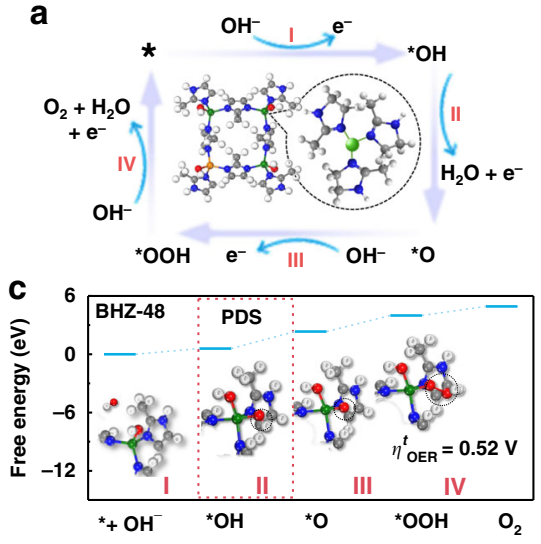

b

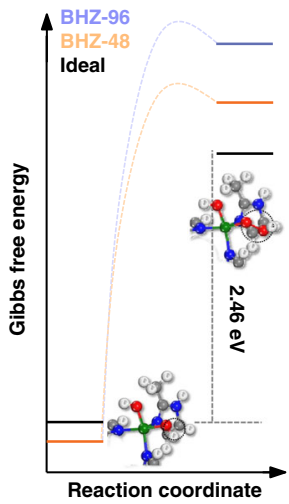

d

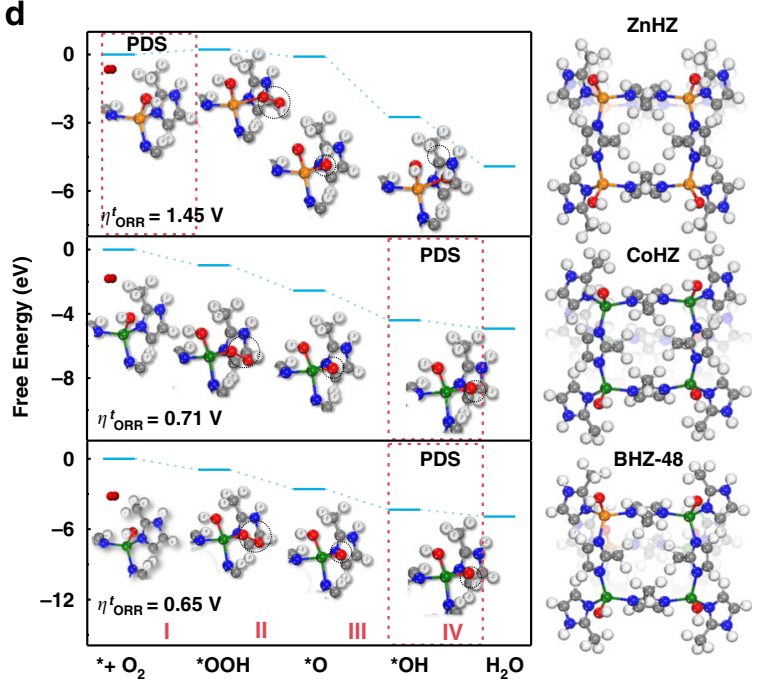

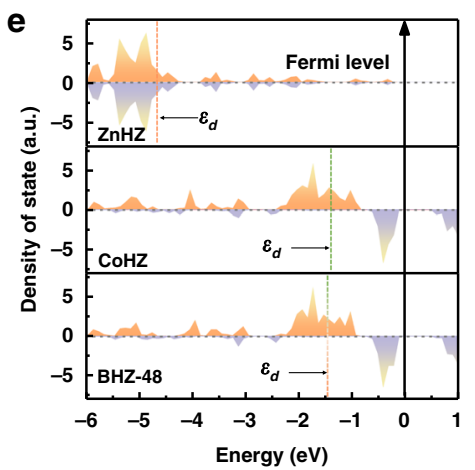
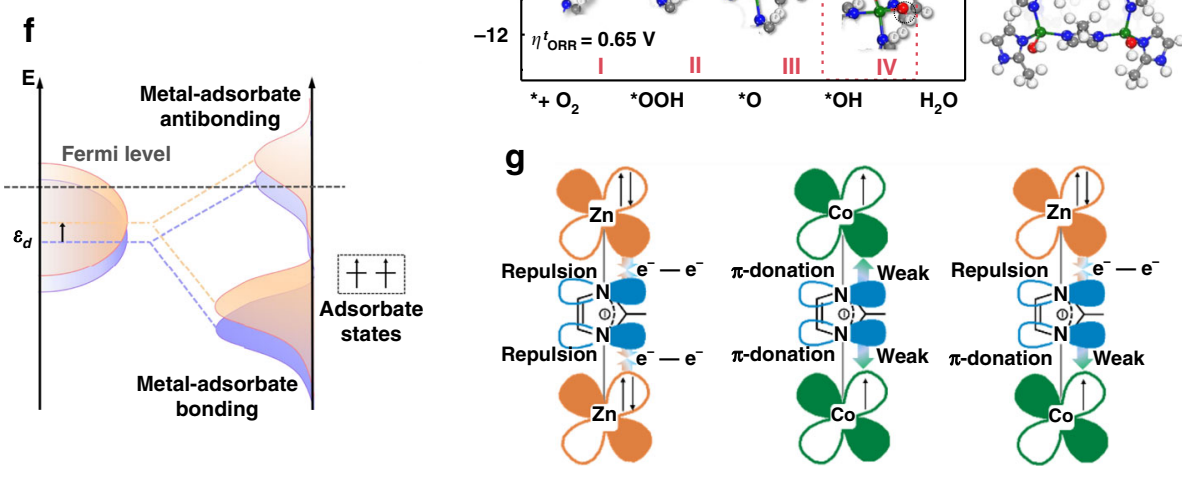

Fig. 6 DFT simulations and proposed mechanism illustration. a Proposed OER catalytic mechanisms for BHZ-48. b Calculated energy barriers of the * ${ }^{*} \mathrm{H}$ transformation to ${ }^{*} \mathrm{OOH}$ at active sites of $\mathrm{BHZ}-48$ and $\mathrm{BHZ}-96$. Gibbs free-energy diagram for $\mathbf{c} \mathrm{OER}$ of $\mathrm{BHZ}-48, \mathbf{d} \mathrm{ORR}$ of $\mathrm{ZnHZ}$, $\mathrm{CoHZ}$, and $\mathrm{BHZ}-48$ with corresponding top views of the structures. Blue, gray, white, red, green, and orange balls represent the $\mathrm{N}, \mathrm{C}, \mathrm{H}, \mathrm{O}, \mathrm{Co}$, and $\mathrm{Zn}$ atoms, respectively. e the calculated $d$ band density of state for the transition metal atoms in $\mathrm{ZnHZ}, \mathrm{CoHZ}$, and $\mathrm{BHZ}-48$. f Schematic illustration explaining change of metaladsorbate interaction by altering the metal $d$ band center $\left(\varepsilon_{d}\right) \cdot \mathbf{g}$ Schematic representations of the electronic coupling between Co and $\mathrm{Zn}$.

BHZ-96 were all prepared using the same procedure, but with different cationexchange reaction time of as-prepared $\mathrm{ZnMZ}$ to $\mathrm{Co}\left(\mathrm{NO}_{3}\right)_{2} \cdot 6 \mathrm{H}_{2} \mathrm{O}$ from $12,24,48$, $60,72,84$, or $96 \mathrm{~h}$. In a typical synthesis of BHZ-48, the as-prepared ZnMZ electrode was immersed into $25 \mathrm{ml}$ methanol containing $1.00 \mathrm{mmol}$ of Co $\left(\mathrm{NO}_{3}\right)_{2} \cdot 6 \mathrm{H}_{2} \mathrm{O}$ for $48 \mathrm{~h}$ at room temperature under airtight conditions. Finally, the $\mathrm{NF}$ was obtained, washed by deionized water, and dried in ambient air.

Synthesis of FeHZ, NiHZ, and CuHZ. The FeHZ, NiHZ, and CuHZ samples were prepared using a similar procedure to that described above for BHZ-48, except that $\mathrm{Co}\left(\mathrm{NO}_{3}\right)_{2} \cdot 6 \mathrm{H}_{2} \mathrm{O}$ were adjusted to $\mathrm{Fe}\left(\mathrm{NO}_{3}\right)_{2}, \mathrm{Ni}\left(\mathrm{NO}_{3}\right)_{2} \cdot 6 \mathrm{H}_{2} \mathrm{O}, \mathrm{Cu}\left(\mathrm{NO}_{3}\right)_{2} \cdot 3 \mathrm{H}_{2} \mathrm{O}$ with same mole number.

Synthesis of BMZ. In all, $0.12 \mathrm{mmol} \mathrm{Zn}\left(\mathrm{NO}_{3}\right)_{2} \cdot 6 \mathrm{H}_{2} \mathrm{O}$ and $0.28 \mathrm{mmol} \mathrm{Co}$ $\left(\mathrm{NO}_{3}\right)_{2} \cdot 6 \mathrm{H}_{2} \mathrm{O}$ were first dissolved in $40 \mathrm{ml}$ deionized water. The solution was then added to $40 \mathrm{ml}$ deionized water containing $0.53 \mathrm{mmol}$ dimethyl imidazole under ultrasonication. Subsequently, a piece of NF was immersed into the mixed solution and transferred into a $100 \mathrm{ml}$ Teflon vessel, which is then reacted at $60^{\circ} \mathrm{C}$ for $24 \mathrm{~h}$ under airtight conditions. After cooling to room temperature, the NF was obtained, washed by deionized water, and then dried in ambient air.

Fabrication of Zn-air battery. Copper foil was used as current collector for the zinc anodes. The BHZ-48 was directly used as the air cathode. Commercial stateof-the-art 30 wt.\% Pt/C and $\mathrm{RuO}_{2}$ catalysts with the same mass loading were measured and compared as the references. Homogeneous catalyst ink consisting of the nanocomposites, ionomer (Nafion solution, $5 \mathrm{wt} . \%$ ) and ethanol was sprayed onto a nickel-based gas diffusion layer (Ion Power Inc., $35 \mathrm{BC}$ ) with a catalyst loading of $1 \mathrm{mg} \mathrm{cm}^{-2}$. The air cathode was then paired with a zinc plate anode and assembled in a battery prototype filled with solution of $6.0 \mathrm{M} \mathrm{KOH}$ and $0.20 \mathrm{M} \mathrm{Zn}$ $\left(\mathrm{CH}_{3} \mathrm{COO}\right)_{2}$. The flexible $\mathrm{Zn}$-air battery was fabricated through layer-by-layer method, and assembled in the order of zinc foil, cellulose membrane, the BHZ-48 and the gas diffusion backing layer. The cellulose membrane was pre-wetted by $6 \mathrm{M}$ $\mathrm{KOH}$ and $0.20 \mathrm{M} \mathrm{Zn}\left(\mathrm{CH}_{3} \mathrm{COO}\right)_{2}$ solution before the battery assembly.

Materials characterization. Transmission electron microscopy images were taken using a JEOL $2010 \mathrm{~F}$ microscope operated at $120 \mathrm{kV}$. X-ray diffraction (XRD) patterns were obtained by a Bruker AXS D8 Advance powder X-ray diffractometer equipped with a $\mathrm{Cu} \mathrm{Ka}$ radiation source $(\lambda=1.5406 \AA)$ and a graphite monochromator. X-ray photoelectron spectroscopy (XPS) measurements were carried out by a Thermal Scientific K-Alpha XPS spectrometer. Wide-angle X-ray scattering (WAXS) images were acquired at Very Sensitive Elemental and Structural Probe Employing Radiation beamline of Canadian Light Source. The energy of Xray beam used for WAXS is $8 \mathrm{keV}$. The X-ray Microdiffraction Analysis software was employed to integrate and obtain the synchrotron X-ray diffraction (SXRD) patterns. X-ray absorption spectroscopy (XAS) measurements on Co and Zn $K$-edge were performed in fluorescence mode at Canadian Light Source, Canada, using Soft X-ray Microcharacterization Beamline and Biological X-Ray Absorption Spectroscopy. Electrodes at different potential conditions were extracted from electrolyzer, sealed and measured immediately. All XAS data were processed using Athena and Artemis software packages. Thickness of the material was characterized by atomic force microscope (Vecco Dimension 3000). Electron-paramagnetic resonance was acquired at $77 \mathrm{~K}$ by a Bruker EMX spectrometer (2-mWmicrowave power, 9.4-GHz microwave frequency). Inductively coupled plasma optical emission spectrometer methodology was conducted on a Thermo Scientific iCAP 6500 duo optical emission spectrometer. Elemental analysis was performed on a Thermo Finnigan FLASH EA 1112 Series. The pore structure was investigated by $\mathrm{N}_{2}$ adsorption-desorption measurements on a Brunauer-Emmett-Teller surface area analyzer (Quantachrome Instruments QuadraSorb SI4) and a Barrett-JoynerHalenda (BJH) model was used to obtain the pore-size distribution.

Electrochemical measurement. The electrochemical measurements were performed in a three-electrode system with an electrochemical workstation (Biologic VMP-3) at ambient temperature and pressure. The three-electrodes system contains the as-fabricated electrodes, a graphite rod, and a reversible hydrogen electrode (RHE) as the working, counter and reference electrodes, respectively. To obtain the linear sweep voltammetry (LSV) curves at different rotating speeds, a rotating disc glassy carbon electrode (GC; $5 \mathrm{~mm}$ in diameter) was used as the working electrode. Acrylic tape $(3 \mathrm{M})$ was used to secure the samples (such as BHZ-48 and Pt/C on nickel foam, $5 \times 5 \mathrm{~mm}^{2}$ ) on the glassy carbon rotating disc electrode tip. Commercial Pt/C (30 wt.\% Pt) and $\mathrm{RuO}_{2}$ catalysts were used as the reference materials. The catalyst ink was prepared by mixing $4 \mathrm{mg}$ of commercial catalyst powder in $1 \mathrm{ml}$ of ethanol containing $0.15 \mathrm{wt} \%$ Nafion ${ }^{\mathrm{TM}}$ dispersion, 
followed by ultrasonication for $1 \mathrm{~h}$. Then $15 \mu \mathrm{l}$ of the as-prepared ink was drop casted onto nickel foam to give a catalyst loading of $0.2 \mathrm{mg} \mathrm{cm}^{-2}$. All the measurements were carried out in $0.1 \mathrm{M} \mathrm{KOH}$ solution, where $\mathrm{O}_{2}$ or $\mathrm{N}_{2}$ gas was purged for $30 \mathrm{~min}$ before ORR or OER measurements, respectively. The LSV measurements were scanned from 1.0 to $0.1 \mathrm{~V}$ for ORR at different rotation speeds and from 1.0 to $1.8 \mathrm{~V}$ for OER at steady state with scan rate of $10 \mathrm{mV} \mathrm{s}^{-1}$. ORR and OER polarization curves were corrected by IR-compensation in $0.1 \mathrm{M} \mathrm{KOH}$ solution, where the resistance is determined by the high-frequency intercept of the Nyquist plot acquired from electrochemical impedance spectroscopy (EIS). The EIS was performed with a frequency ranging from $100 \mathrm{kHz}$ to $0.1 \mathrm{~Hz}$ with potential amplitude of $50 \mathrm{mV}$. Capacitive background currents were subtracted for ORR and OER polarization curves during cyclic voltammetry (CV) measurements in $\mathrm{N}_{2^{-}}$ saturated $\mathrm{KOH}$ solution. The stability studies on the half-cell reactions (ORR and OER separately) was primarily assessed by chronoamperometric and chronopotentiometric measurements at a given constant potential or a constant current for $300 \mathrm{~h}$. Galvanostatic discharge and charge cycling of the $\mathrm{Zn}$-air batteries was performed through a recurrent galvanic pulse method at current densities of 15 $\mathrm{mA} \mathrm{cm}{ }^{-2}$ with $10 \mathrm{~h}$ per cycle. These galvanostatic charge/discharge curves were recorded using a LAND battery testing station (CT2001A) at room temperature. Polarization data was collected using the galvanodynamic method at a scan rate of $1.0 \mathrm{~mA} \mathrm{~s}^{-1}$ with cut-off voltages of $0.5 \mathrm{~V}$ for the discharge curves and $2.5 \mathrm{~V}$ for the charge curves.

Computational details. All the spin-polarized computations were performed by using Vienna ab initio simulation package (VASP). The ion-electron interactions were described by the projector augmented wave method and the general gradient approximation in the Perdew-Burke-Ernzerhof (PBE) form was used. During the structure relaxation, the convergence criterion was set to $0.05 \mathrm{eV}^{-1}$ and $10^{-5} \mathrm{eV}$ for the residual force and energy, respectively. The models we used to simulate the BHZ-96, BHZ-48, ZnHZ and CoHZ. For BHZ-48, ZnHZ and CoHZ, the metal sites are terminated by $\mathrm{OH}$ group, owing to the high surface free energy of the metal atoms. To avoid the interaction between two periodic units, a vacuum space of $20 \AA$ was employed.

The OER may proceed through the following elementary steps (Eqs. (1-4)), which are usually employed to investigate the electrocatalysis of the OER on various materials:

$$
\begin{gathered}
\mathrm{OH}^{-}(\mathrm{aq})+{ }^{*} \rightarrow{ }^{*} \mathrm{OH}+\mathrm{e}^{-} \\
\mathrm{OH}^{-}(\mathrm{aq})+{ }^{*} \mathrm{OH} \rightarrow{ }^{*} \mathrm{O}+\mathrm{H}_{2} \mathrm{O}+\mathrm{e}^{-} \\
\mathrm{OH}^{-}(\mathrm{aq})+{ }^{*} \mathrm{O} \rightarrow{ }^{*} \mathrm{OOH}+\mathrm{e}^{-} \\
\mathrm{OH}^{-}(\mathrm{aq})+{ }^{*} \mathrm{OOH} \rightarrow \mathrm{O}_{2}+\mathrm{H}_{2} \mathrm{O}+\mathrm{e}^{-}+*
\end{gathered}
$$

The ORR occurring through elementary steps takes the reverse direction of OER (Eqs. (5-8)):

$$
\begin{gathered}
\mathrm{O}_{2}+\mathrm{H}_{2} \mathrm{O}+\mathrm{e}^{-}+{ }^{*} \rightarrow{ }^{*} \mathrm{OOH}+\mathrm{OH}^{-}(\mathrm{aq}) \\
{ }^{*} \mathrm{OOH}+\mathrm{e}^{-} \rightarrow \mathrm{OH}^{-}(\mathrm{aq})+{ }^{*} \mathrm{O} \\
{ }^{*} \mathrm{O}+\mathrm{H}_{2} \mathrm{O}+\mathrm{e}^{-} \rightarrow{ }^{*} \mathrm{OH}+\mathrm{OH}^{-}(\mathrm{aq}) \\
{ }^{*} \mathrm{OH}+\mathrm{e}^{-} \rightarrow \mathrm{OH}^{-}(\mathrm{aq})+*
\end{gathered}
$$

The free-energy change $(\Delta G)$ of each elementary reaction was calculated as

$$
\Delta G=\Delta E+\Delta E_{\mathrm{ZPE}}-T \Delta S
$$

In Eq. (9), $\Delta E, E_{\mathrm{ZPE}}, T$, and $S$ is the reaction energy difference, zero-point energies, temperature and entropy, respectively.

\section{Data availability}

The data that support the findings of this study are available from the corresponding author upon reasonable request.

Received: 8 June 2020; Accepted: 9 October 2020;

Published online: 17 November 2020

\section{References}

1. Li, Y. \& Lu, J. Metal-air Batteries: will they be future electrochemical energy storage of choice? ACS Energy Lett. 2, 1370 (2017).

2. Cao, R., Lee, J. S., Liu, M. \& Cho, J. Recent progress in non-precious catalysts for metal-air batteries. Adv. Energy Mater. 2, 816-829 (2012).

3. Fu, J. et al. Electrically rechargeable zinc-air batteries: progress, challenges, and perspectives. Adv. Mater. 29, 1604685 (2017).

4. Lee, J.-S. et al. Metal-air batteries with high energy density: Li-air versus Znair. Adv. Energy Mater. 1, 34-50 (2011).
5. Tang, C., Wang, H. F. \& Zhang, Q. Multiscale principles to boost reactivity in gas-involving energy electrocatalysis. Acc. Chem. Res. 51, 881-889 (2018).

6. Liu, Q., Chang, Z., Li, Z. \& Zhang, X. Flexible metal-air batteries: progress, challenges, and perspectives. Small Methods 2, 1700231 (2018).

7. Wang, H.-F., Tang, C. \& Zhang, Q. A review of precious-metal-free bifunctional oxygen electrocatalysts: rational design and applications in $\mathrm{Zn}$ - air batteries. Adv. Funct. Mater. 28, 1803329 (2018).

8. Wang, X. et al. High-performance platinum-perovskite composite bifunctional oxygen electrocatalyst for rechargeable $\mathrm{Zn}$-air battery. Adv. Energy Mater. 10, 1903271 (2019).

9. Liu, X. et al. Integrating NiCo alloys with their oxides as efficient bifunctional cathode catalysts for rechargeable Zinc-air batteries. Angew. Chem. Int. Ed. 54 9654-9658 (2015).

10. Yu, J., Li, B. Q., Zhao, C. X., Liu, J. N. \& Zhang, Q. Asymmetric air cathode design for enhanced interfacial electrocatalytic reactions in high-performance zinc-air batteries. Adv. Mater. 32, e1908488 (2020).

11. $\mathrm{Li}, \mathrm{Y}$. et al. Atomically thin mesoporous $\mathrm{Co}_{3} \mathrm{O}_{4}$ layers strongly coupled with $\mathrm{N}-\mathrm{rGO}$ nanosheets as high-performance bifunctional catalysts for 1D knittable zinc-zir batteries. Adv. Mater. 30, 1703657 (2018).

12. Meng, F., Zhong, H., Bao, D., Yan, J. \& Zhang, X. In situ coupling of strung Co4N and intertwined $\mathrm{N}-\mathrm{C}$ fibers toward free-standing bifunctional cathode for robust, efficient, and flexible $\mathrm{Zn}$-air batteries. J. Am. Chem. Soc. 138, 10226-10231 (2016).

13. Li, B. Q., Zhao, C. X., Liu, J. N. \& Zhang, Q. Electrosynthesis of hydrogen peroxide synergistically catalyzed by atomic $\mathrm{Co}-\mathrm{Nx}-\mathrm{C}$ sites and oxygen functional groups in noble-metal-free electrocatalysts. Adv. Mater. 31, e1808173 (2019).

14. Xie, J. et al. From supramolecular species to self-templated porous carbon and metal-doped carbon for oxygen reduction reaction catalysts. Angew. Chem. Int. Ed. 58, 4963-4967 (2019).

15. Tian, $\mathrm{Y}$. et al. $\mathrm{Fe}_{3} \mathrm{C} / \mathrm{Fe}_{2} \mathrm{O}_{3}$ heterostructure embedded in $\mathrm{N}$-doped graphene as a bifunctional catalyst for quasi-solid-state zinc-air batteries. Carbon 146, 763-771 (2019).

16. Nam, G. et al. A ternary $\mathrm{Ni}_{46} \mathrm{Co}_{40} \mathrm{Fe}_{14}$ nanoalloy-based oxygen electrocatalyst for highly efficient rechargeable zinc-air batteries. Adv. Mater. 30, e1803372 (2018).

17. Deng, Y.-P. et al. Dynamic electrocatalyst with current-driven oxyhydroxide shell for rechargeable zinc-air battery. Nat. Commun. 11, 1952 (2020).

18. Li, B.-Q. et al. Regulating p-block metals in perovskite nanodots for efficient electrocatalytic water oxidation. Nat. Commun. 8, 934 (2017).

19. Li, C. et al. Phase and composition controllable synthesis of cobalt manganese spinel nanoparticles towards efficient oxygen electrocatalysis. Nat. Commun. 6, 7345 (2015).

20. Jiang, Y. et al. Interpenetrating triphase cobalt-based nanocomposites as efficient bifunctional oxygen electrocatalysts for long-lasting rechargeable $\mathrm{Zn}$ air batteries. Adv. Energy Mater. 8, 1702900 (2018).

21. Lu, X. F., Chen, Y., Wang, S., Gao, S. \& Lou, X. W. Interfacing manganese oxide and cobalt in porous graphitic carbon polyhedrons boosts oxygen electrocatalysis for Zn-air batteries. Adv. Mater. 31, e1902339 (2019).

22. Deng, Y.-P. et al. Hierarchical porous double-shelled electrocatalyst with tailored lattice alkalinity toward bifunctional oxygen reactions for metal-air batteries. ACS Energy Lett. 2, 2706-2712 (2017).

23. Tang, C., Wang, B., Wang, H. F. \& Zhang, Q. Defect engineering toward atomic $\mathrm{Co}-\mathrm{Nx}-\mathrm{C}$ in hierarchical graphene for rechargeable flexible solid $\mathrm{Zn}$ air batteries. Adv. Mater. 29, 1703185 (2017).

24. Li, B. Q. et al. Framework-porphyrin-derived single-atom bifunctional oxygen electrocatalysts and their applications in $\mathrm{Zn}$-air batteries. Adv. Mater. 31, 1900592 (2019).

25. Deng, Y.-P. et al. The current state of aqueous $\mathrm{Zn}$-based rechargeable batteries. ACS Energy Lett. 5, 1665-1675 (2020).

26. $\mathrm{Li}$, J. et al. Atomically dispersed manganese catalysts for oxygen reduction in proton-exchange membrane fuel cells. Nat. Catal. 1, 935 (2018).

27. Chenitz, R. et al. A specific demetalation of $\mathrm{Fe}-\mathrm{N}_{4}$ catalytic sites in the micropores of NC_Ar $+\mathrm{NH}_{3}$ is at the origin of the initial activity loss of the highly active $\mathrm{Fe} / \mathrm{N} / \mathrm{C}$ catalyst used for the reduction of oxygen in PEM fuel cells. Energy Environ. Sci. 11, 365-382 (2018).

28. Wu, H. B., Xia, B. Y., Yu, L., Yu, X.-Y. \& Lou, X. W. Porous molybdenum carbide nano-octahedrons synthesized via confined carburization in metalorganic frameworks for efficient hydrogen production. Nat. Commun. 6, 6512 (2015).

29. Zhong, H. et al. Synergistic electroreduction of carbon dioxide to carbon monoxide on bimetallic layered conjugated metal-organic frameworks. Nat. Commun. 11, 1409 (2020)

30. Liu, S. et al. Metal-organic-framework-derived hybrid carbon nanocages as a bifunctional electrocatalyst for oxygen reduction and evolution. Adv. Mater. 29, 1700874 (2017).

31. Jian, M., Liu, B., Zhang, G., Liu, R. \& Zhang, X. Adsorptive removal of arsenic from aqueous solution by zeolitic imidazolate framework-8 (ZIF-8) nanoparticles. Colloids Surf. A Physicochem. Eng. Asp. 465, 67-76 (2015). 
32. Choi, J.-Y. et al. Is the rapid initial performance loss of Fe/N/C non precious metal catalysts due to micropore flooding? Energy Environ. Sci. 10, 296-305 (2017).

33. Lu, X. F., Xia, B. Y., Zang, S. Q. \& Lou, X. W. Metal-organic frameworks based electrocatalysts for the oxygen reduction reaction. Angew. Chem. Int. Ed. 59, 4634-4650 (2020).

34. Ren, D. et al. Hierarchically porous multimetal-based carbon nanorod hybrid as an efficient oxygen catalyst for rechargeable zinc-air batteries. Adv. Funct. Mater. 30, 1908167 (2020).

35. Yang, Q. et al. Regulating the spatial distribution of metal nanoparticles within metal-organic frameworks to enhance catalytic efficiency. Nat. Commun. 8, 14429 (2017)

36. Jakšić, M. M. Advances in electrocatalysis for hydrogen evolution in the light of the Brewer-Engel valence-bond theory. J. Mol. Catal. 38, 161-202 (1986).

37. Jiang, J. et al. Atomic-level insight into super-efficient electrocatalytic oxygen evolution on iron and vanadium co-doped nickel (oxy) hydroxide. Nat. Commun. 9, 2885 (2018).

38. Müller, M. et al. Au@MOF-5 and Au/MOx@MOF-5 $(M=Z n, T i ; x=1,2)$ : preparation and microstructural characterisation. Eur. J. Inorg. Chem. 2011, 1876-1887 (2011).

39. $\mathrm{Fu}, \mathrm{X}$. et al. In situ polymer graphenization ingrained with nanoporosity in a nitrogenous electrocatalyst boosting the performance of polymer-electrolytemembrane fuel cells. Adv. Mater. 29, 1604456 (2017).

40. Jaouen, F., Lefèvre, M., Dodelet, J.-P. \& Cai, M. Heat-treated Fe/N/C catalysts for $\mathrm{O}_{2}$ electroreduction: are active sites hosted in micropores? J. Phys. Chem. B 110, 5553-5558 (2006)

41. Wan, X. et al. Fe-N-C electrocatalyst with dense active sites and efficient mass transport for high-performance proton exchange membrane fuel cells. Nat. Catal. 2, 259-268 (2019).

42. Zhang, L., Wu, H. B. \& Lou, X. W. Metal-organic-frameworks-derived general formation of hollow structures with high complexity. J. Am. Chem. Soc. 135, 10664-10672 (2013).

43. Au-Duong, A. N. \& Lee, C. K. Iodine-loaded metal organic framework as growth-triggered antimicrobial agent. Mater. Sci. Eng. C. Mater. Biol. Appl. 76, 477-482 (2017).

44. Li, L. et al. A synthetic route to ultralight hierarchically micro/mesoporous $\mathrm{Al}$ (III)-carboxylate metal-organic aerogels. Nat. Commun. 4, 1774 (2013).

45. Wang, H.-F. et al. Defect-rich carbon fiber electrocatalysts with porous graphene skin for flexible solid-state zinc-air batteries. Energy Stor. Mater. 15 124-130 (2018).

46. Xiao, Z. et al. Filling the oxygen vacancies in $\mathrm{Co}_{3} \mathrm{O}_{4}$ with phosphorus: an ultraefficient electrocatalyst for overall water splitting. Energy Environ. Sci. 10, 2563-2569 (2017).

47. Pratesi, A. et al. Dioxygen oxidation $\mathrm{Cu}(\mathrm{II})->\mathrm{Cu}(\mathrm{III})$ in the copper complex of cyclo(Lys-dHis-betaAla-His): a case study by EXAFS and XANES approach. Inorg. Chem. 51, 7969-7976 (2012).

48. Park, J. et al. Single crystalline pyrochlore nanoparticles with metallic conduction as efficient bi-functional oxygen electrocatalysts for $\mathrm{Zn}$-air batteries. Energy Environ. Sci. 10, 129-136 (2017).

49. $\mathrm{Fu}$, J. et al. Defect engineering of chalcogen-tailored oxygen electrocatalysts for rechargeable quasi-solid-state zinc-air batteries. Adv. Mater. 29, 1702526 (2017).

50. Tang, C., Zhong, L., Zhang, B., Wang, H. F. \& Zhang, Q. 3D Mesoporous van der waals heterostructures for trifunctional energy electrocatalysis. $A d v$. Mater. 30, 1705110 (2018).

51. Liu, G. et al. An oxygen-vacancy-rich semiconductor-supported bifunctional catalyst for efficient and stable zinc-zir batteries. Adv. Mater. 31, 1806761 (2019).

52. Zhao, M. et al. Electrochemical phase evolution of metal-based pre-catalysts for high-rate polysulfide conversion. Angew. Chem. Int. Ed. 59, 9011-9017 (2020).

53. Cano, Z. P. et al. Batteries and fuel cells for emerging electric vehicle markets. Nat. Energy 3, 279 (2018).

54. Wang, Y. et al. Missing-node directed synthesis of hierarchical pores on a zirconium metal-organic framework with tunable porosity and enhanced surface acidity via a microdroplet flow reaction. J. Mater. Chem. A 5, 22372-22379 (2017).
55. Huang, Z.-F. et al. Strategies to break the scaling relation toward enhanced oxygen electrocatalysis. Matter 1, 1494-1518 (2019).

56. Xiao, M. et al. A single-atom iridium heterogeneous catalyst in oxygen reduction reaction. Angew. Chem. Int. Ed. 131, 9640-9645 (2019).

57. Georgiadis, R. \& Armentrout, P. B. Kinetic energy dependence of the reactions of $\mathrm{Ca}^{+}$and $\mathrm{Zn}^{+}$with $\mathrm{H} 2, \mathrm{D} 2$, and HD. effect of empty versus full d orbitals. $J$ Phys. Chem. 7060-7067 (1988).

58. Patino, R., Campos M. \& Torres, L. A. Strength of the Zn-N coordination bond in zinc porphyrins on the basis of experimental thermochemistry. Inorg. Chem. 46, 9332-9336 (2007).

59. Notario, R. Strong Chemical Bonds. Encyclopedia of Physical Organic Chemistry (John Wiley \& Sons, 2016).

\section{Acknowledgements}

We would like to acknowledge the financial support from the Natural Sciences and Engineering Research Council of Canada (NSERC), the University of Waterloo, and the Waterloo Institute for Nanotechnology. We also thank the Dr. Renfei Feng at Very Sensitive Elemental and Structural Probe Employing Radiation from a Synchrotron (VESPERS), Dr. Qunfeng Xiao at Soft X-Ray Microcharacterization Beamline (SXRMB), Dr. Roman Chernikov and Dr. Emilio Heredia at Biological X-Ray Absorption Spectroscopy (BioXAS) from Canadian Light Source (CLS) for WAXS and XAS measurement. The CLS is supported by the NSERC, the National Research Council Canada, the Canadian Institutes of Health Research, the Province of Saskatchewan, Western Economic Diversification Canada, and the University of Saskatchewan.

\section{Author contributions}

Z.C. and A.Y. proposed the research direction, conceived, and led the project. Y.J. and Y.-P.D designed and performed the experiments. Z.C., Y.J., Y.-P.D., R.L., J.F., D.L., and Z B. analyzed and discussed the experimental results and drafted the manuscript. Y.J., Y.-P. D., R.G., and Y.H. performed the XAS experiments and analyzed the data. All authors participated in discussions and gave useful suggestions.

\section{Competing interests}

The authors declare no competing interests.

\section{Additional information}

Supplementary information is available for this paper at https://doi.org/10.1038/s41467 020-19709-6.

Correspondence and requests for materials should be addressed to Z.C.

Peer review information Nature Communications thanks Guntae Kim and the other, anonymous, reviewers for their contribution to the peer review of this work.

Reprints and permission information is available at http://www.nature.com/reprints

Publisher's note Springer Nature remains neutral with regard to jurisdictional claims in published maps and institutional affiliations.

Open Access This article is licensed under a Creative Commons Attribution 4.0 International License, which permits use, sharing, adaptation, distribution and reproduction in any medium or format, as long as you give appropriate credit to the original author(s) and the source, provide a link to the Creative Commons license, and indicate if changes were made. The images or other third party material in this article are included in the article's Creative Commons license, unless indicated otherwise in a credit line to the material. If material is not included in the article's Creative Commons license and your intended use is not permitted by statutory regulation or exceeds the permitted use, you will need to obtain permission directly from the copyright holder. To view a copy of this license, visit http://creativecommons.org/ licenses/by/4.0/

(C) The Author(s) 2020 